\title{
That's not my Robert! Identity maintenance and other warrants in family members' claims about mistreatment in old-age care
}

\author{
TOVE HARNETT* and HÅKAN JÖNSON†
}

\begin{abstract}
This study has explored how family members of care recipients define and sustain claims of mistreatment in old-age care. Twenty-one informants were recruited from an association of relatives of care recipients in Sweden. Using argumentation analysis, four warrants about mistreatment were identified from the qualitative interview data: they referred to physical harm, psychological harm, social-care deficiencies and identity subversion. The first three categories are similar to those recognised in previous research on elder mistreatment, but the fourth, which is described in detail in the article, is less familiar: elder mistreatment as the violation of an older person's identity. The family members backed their claims about staff members' violation of a care recipient's persona or identity by using arguments that drew on their unique knowledge of the care recipient's appearance, daily routines and preferred activities. They also described their attempts to protect the dignity and identity of a care recipient, their fears of abuse, and actual cases of conflict and retribution by care staff. They consistently positioned themselves as guardians of identity through their claims of mistreatment. The study provides important knowledge about family members' moral view of elder mistreatment, which may enhance the understanding of conflicts between formal care providers and family members.
\end{abstract}

$\boldsymbol{K E Y} \boldsymbol{W} \boldsymbol{W} \boldsymbol{R} \boldsymbol{S}$ - claims-making, elder abuse, elder care, family members, mistreatment, person-centred care, relatives, warrants.

\section{Introduction}

This paper examines certain interactions between the staff of residential institutions for older people and the relatives of the care recipients, and the family members' evaluations of the care. When a daughter of a resident was asked how she defined elder mistreatment in formal care,

* Institute of Gerontology, School of Health Sciences, Jönköping University, Jönköping, Sweden.

$\dagger$ Department of Social Work, Lund University, Lund, Sweden. 
she claimed that her father, Robert, was being mistreated by the staff. She explained that on many of her visits to the nursing home, her father had been dressed in a T-shirt and tracksuit pants. How can it be 'mistreatment' to dress a person in soft and comfortable clothes, when the person in question is frail and spends the whole day sitting? In this particular case, the daughter argued that dressing her father in a T-shirt and tracksuit pants 'was awful' because he came from a family of landowners where a different dress code applied. Before moving into residential care, he had always dressed 'properly' and would never have worn a T-shirt. The argument underlying the daughter's claim of 'mistreatment' refers to a norm about the maintenance of the identity of the institutionalised person. Regardless of comfort, improper dressing was, according to the interviewee, a violation of her father's persona and identity. The issue had produced conflict, and the daughter had removed some clothes from her father's wardrobe.

This study explores the ways in which family members of care recipients define mistreatment in old-age care, and how their views lead to a better understanding of conflicts between family members and care staff. We use the term mistreatment (Hudson I99I) to avoid the problem of judging whether a certain phenomenon should be labelled as elder abuse or neglect: the broader term reflects the claim that a certain action, event or condition is harmful and morally wrong (compare with Hydle and Johns 1993). Despite the recognition that reflective practice in the area of elder mistreatment must be guided by theoretical awareness (Gearing I995; Teaster, Lawrence and Cecil 2007), in the literature and in research on elder abuse and neglect there has been little attention to theory (Harbison and Morrow 1998). We suggest that findings from a theoretically guided study of family members' perspectives will contribute to our understanding in two ways: they will add valuable knowledge, first, about family members' understanding of mistreatment, which has received little attention in previous research, and, second, about family members' perspectives on optimal or ideal care, which may increase our understanding of their conflicts with staff. The specific aims of the research were:

- To analyse what family members perceive as mistreatment, as well as how they rhetorically construct what elder mistreatment is and is not.

- To understand what normative grounds, or warrants, family members use in their arguments about mistreatment.

- To discuss how these warrants can be used to increase understanding about conflicts between staff and family members.

Particular attention will be devoted to the ways in which family members define mistreatment in relation to their adopted role as 'guardians of 
dignity'. This role has been identified as crucial to the understanding of how many family members define their relations with formal care providers (Whitaker 2004). Given that different family members may have contradictory views about a care recipient, as well as about mistreatment as a phenomenon, we have not sought to over-generalise the findings.

\section{The professional construction of mistreatment}

Mistreatment in formal old-age care is nothing new, and there have been reports of elder abuse and care deficiencies over several decades since and before the seminal studies of Townsend (ig62) and Robb (Ig67). From the mid-I970s, mistreatment, both within the family and in formal care settings, has received increased societal attention, and considerable effort has been devoted to finding a comprehensive definition (Hugman I995; Plitnick 2008; Roe 2002). Alongside the definitions proposed by prominent researchers (Glendenning i997; Isola et al. 2003; Pillemer and Moore ig89; Saveman I994; Saveman et al. I999), expert panels and various schema have been used in search of a consensus about what to regard as elder mistreatment (Hudson I99I ; Sellers, Folts and Logan I992). Mistreatment is usually said to include the use of physical, verbal, psychological, economic, social or sexual abuse, intentional or unintentional neglect, or a failure to care. Although researchers have defined the phenomenon of elder mistreatment variously, most definitions primarily reflect the perspectives of care professionals. The inference is that professionals are able to describe what mistreatment is (and is not), and that staff have a key role in reporting and estimating the prevalence of mistreatment in institutional settings (Baker and Heitkemper 2005; Brogden and Nijhar 2000; Cooper, Selwood and Livingston 2008; Harbinson and Morrow I998; Lachs and Pillemer 2004; Shore and Santy 2004). An obvious reason for the dominance of professionals' perspectives in old-age care is the relative absence of care recipients' voices in research on mistreatment (Nandlal and Wood I997). Care recipients occupy a vulnerable position that makes them reluctant to report problems, and some suffer from confusion or dementia. Professionals are 'at the scene' and in research on mistreatment have to a great extent attempted to speak for the care recipient.

\section{Person-centred care and family members as guardians}

Given the absence of care recipients' voices, the views of family members may deepen our understanding of the phenomenon of mistreatment. 
It is increasingly advocated that families are more involved in the formal care system (Åkerström i996; Rolland ı994; Whitaker 2009). The person-centred care paradigm that has taken hold during the last few decades emphasises the need for care workers to learn about the 'whole life' of older individuals (typically using a biographical approach), so that care can be tailored accordingly (National Care Homes Research and Development Forum 2007). Many writers that subscribe to this paradigm have emphasised that information from family members can provide important biographical details, and that family contacts and involvement help sustain a resident's identity (e.g. Boise and White 2004; Bowers I988; Duncan and Morgan 1994; Hertzberg and Ekman 2000). Still, few have discussed this 'preservation work' in relation to either the perception of mistreatment or to disagreements and conflicts about a resident's personality and identity. The role of family members as part of the consumer advocacy movement in the United States of America has been discussed by Phillips et al. (2008), but research on mistreatment generally places family members on the periphery and outside the scope of the inquiry (Davies and Nolan 2003; Nandlal and Wood i997).

One reason for the absence of a family members' perspective may be that care work has traditionally been constructed in terms of the relationship between two parties - care-givers and care-receivers (Eliasson 1995). In fact, even some studies that claim a person-centred care approach follow this construction (Adams 2005; compare with McCormack 2003). In research and practice on mistreatment within the family, there has been a tendency for the professional perspective to construct care relationships in terms of an older victim, a perpetrating family member, and the intervening professional (Brogden and Nijhar 2000). The definition and model intervention suggested by Hydle and Johns (I993) are illuminating. Their model requires three players (victim, perpetrator and witness), and the role of the professional is to judge whether mistreatment is occurring and to decide how to intervene in the conflictive dyad. The institutionalisation of the victim is frequently the solution to the problem (Hydle and Johns I993). For many years, the 'family violence model' has been the dominant approach to elder mistreatment (Glendenning 1999), but roles and relations may look very different when an older person receives formal care. Whitaker (2004, 2009; compare with High and Rowles 1995) used the expression 'guardians of dignity' to describe the role that family members believe they played in relation to the providers of residential care. It is possible that a position as 'guardian' will produce definitions of mistreatment that differ from professional perspectives. When attempting to prevent mistreatment and secure good care, family members may also fear that members of staff will take offence at being 
criticised, which has been described as being in a 'hostage situation' (Jönson 2006).

\section{Data collection and participants}

The informants were recruited from an association for relatives of care recipients. A representative of this association sent a description of the study to 6o randomly selected members, with a request to contact the second author if a family member had received formal care and was willing to participate. Twenty-one interviews were conducted by the second author, and they lasted between 35 and 98 minutes (mean 6i minutes). ${ }^{1}$ Of the 23 relatives that participated, I5 were women and eight men, and their ages ranged from 54 to 84 years. Twenty-four care recipients were described, I2 women and I 2 men, and they included I 2 spouses, ten parents or parents-in-law, and two siblings. Eight care recipients had died. Various care arrangements were described, partly reflecting the fact that some care recipients had received home care, respite care and day care before moving into permanent residential care.

Since the members of the relatives' association include care recipients as well as informal care-givers and support members, it is incorrect to calculate the response rate as $2 \mathrm{I}$ interviews out of 6o. For instance, nine people called to inform us that they did not belong in the study population, even though the letter from the researchers had stated that if this was the case, they could ignore the request. An important aspect of the recruitment procedure was that the family members self-identified as engaged in care, which would have been difficult to ensure if the interviewees had been recruited through care-provider organisations. The procedure might have introduced bias, however, by over-representing those with very strong feelings about the care that their relatives received, and indeed we expected to hear horror stories and negative accounts about care arrangements. Since the aim of the study was not to establish the prevalence of mistreatment, this was deemed a minor problem, and as it turned out, the relatives' views about the care were generally balanced or positive. The interview guide included questions about: the care received and how the arrangements were perceived by the interviewees (and care recipients); the interviewees' opinions on abuse, neglect and other forms of mistreatment; definitions, causes and seriousness of problems; solutions; and the role of family members. After these questions, the interviewee was asked to describe their own observations of defective care, and finally to articulate their understanding of physical abuse, psychological abuse, sexual abuse, economic abuse and neglect. ${ }^{2}$ 


\section{The analysis and theoretical framework}

Both authors listened to the recorded interviews and read the transcriptions separately. During the second phase of the analysis, the interviews were systematically and repeatedly scanned for sections in which claims about mistreatment were made. The aim was to work through the data, collecting candidate examples of claims about mistreatment. In analysing the data, we relied upon 'analytic bracketing' as described by Gubrium and Holstein (1997). How interviewees' claims about mistreatment were rhetorically constructed and which normative grounds were used by the interviewees was as important as what was being expressed (i.e. what the interviewees perceived as elder mistreatment). Rather than simply enumerating the claims about mistreatment, the aim of the analysis was to understand what different normative grounds, or warrants, the interviewees used to back up their claims. In this study, the term claim refers to statements about actions, events or conditions that should be regarded as mistreatment (n.b. in a similar study, Best (1990) used the term conclusion for such statements). In the interviews, claims typically appeared as stories told about actions, events or conditions in response to the question: what constitutes mistreatment? In many cases, the interviewees had acted in accordance with their claims (e.g. by complaining or reporting problems).

Guided by Toulmin's (2003) basic structure of argumentation, the analysis had two stages, with the key element being the concept of warrants, one of the three main components of Toulmin's theory (the others being data or the facts and claims). Toumlin portrayed an argument as reasoning 'from accepted data, through a warrant, to a claim'. Warrants are implicit or explicit normative grounds that justify the interpretation of the data and the conclusions. Because it is in the warrants that people's values most often come into play, they are of particular interest in research on values and norms. If the listener disagrees about the warrant, the whole argument will be judged as rhetorically invalid (Toulmin 2003). The case with which we began the paper, about the improper dressing of Robert, elucidates the interplay between Toulmin's theoretical components:

- Data: The staff dressed my father in a T-shirt and tracksuit pants.

- Claim: My father was a victim of mistreatment because they dressed him in a way that is not in line with his person.

- Warrant (implicit): The subversion of a care recipient's identity is elder mistreatment.

- Backing argument: He has always dressed like a proper gentleman and never used to wear a T-shirt and tracksuit pants. ${ }^{3}$ 
Every argument makes an assertion or claim that begins with the data. Knowing the data and the claim will not necessarily convince others that the claim is a reasonable inference from the data. In the example above, knowing that a resident of a nursing home was dressed in a $\mathrm{T}$-shirt and tracksuit pants does not itself convince that he was mistreated. A mechanism, standard or warrant is required to justify the claim. This justification is known as the warrant. In the example above, the implicit warrant acts as the bridge between the data and the claim and is supported by a backing argument about the way the resident always used to dress. If the proponent of a claim feels that the listener accepts the normative grounds, then references to the warrants may be absent, understated or implicit. This is more likely in claims made during an interview or in a naturally occurring situation, as compared to claims-making in official settings (Best i99o).

The analysis was guided by inductive reasoning, although driven by an initial interest in family members' reasoning about mistreatment. Each excerpt of argument or reasoning that somehow related to claims of mistreatment was identified and tentatively categorised. As the examples multiplied, the initial categories were modified and generalised, and eventually they encompassed the great diversity of the occurrences. Initially we identified three major types of warrants that related to physical harm, psychological harm, and the failure to meet socialcare needs. These themes are close to those identified by previous research on elder mistreatment (Hudson I99I). Through further analysis, however, we also discovered that many of the claims about mistreatment did not fit any of these categories and seemed to be grounded in warrants about the individual's identity, so we created a fourth category of warrants that was named 'identity subversion'. This finding would most likely not have been forthcoming without the inductive approach.

In sum, the analysis identified four categories of warrants that figured prominently as the moral bases of the family members' claims about mistreatment. These categories are to be understood as the interviewees' normative grounds in claims-making; that is to say, the recurrent and systematic norms that they explicitly or implicitly referred to in their accounts of mistreatment. According to these warrants, elder mistreatment constituted:

- Inflicting physical harm and/or failing to meet the physical needs of care recipients.

- Inflicting psychological harm and/or displaying bad manners in relation to care recipients. 
- Failing to meet the social needs of care recipients.

- Subverting the identity of care recipients through a lack of respect for their personality and habits.

As mentioned, the first three categories echo those from mainstream elder mistreatment research (Hudson I99I), while the fourth category has not previously been identified. As will be apparent, the warrants overlap but each has specific features, and the next sections discuss each in turn. We focus on an aspect of mistreatment that appeared as paramount in the interviews and may be a unique perspective of family members, namely their role as guardians of identity.

\section{Warrants about physical harm}

It is mistreatment to inflict physical harm and/or fail to meet physical care needs

Inappropriate physical care was frequently mentioned in the interviewees' claims about elder mistreatment. Claims grounded in warrants about physical harm appeared in their accounts of inappropriate medication, badly treated pressure sores, and the neglect of oral/dental care. In several 'guardianship stories', the interviewees stated that if they had not been present, the mistreatment would not have been discovered, and in some cases the consequences would have been fatal. In a typical story, a woman described how her mother displayed pains in her leg and the staff simply took morphine from the cupboard of another resident. Eventually it was discovered that her mother suffered from an in-growing toenail, which caused great suffering but is easily treated. The daughter grounded her claim about mistreatment using a warrant about physical harm. That harm had been the result of the wrongful medication was implied in, 'so they gave her morphine for that! And of course that affected her breathing'. In this story, the interviewee emphasised the staff members' negligence, described her own position, her struggle to initiate action, and the resolution of the situation. She concluded that she was right to protest against the unauthorised medication and to allege mistreatment.

Most people would agree that morphine should be prescribed only by doctors, and that strong sedatives must not substitute for the treatment of minor health problems, but some family members' claims of physical harm were contested by the professional carers. For example, a man related that a doctor diagnosed his wife, a resident in a nursing home, as suffering from pneumonia and said no treatment was needed because 'pneumonia is the older person's best friend? ... It means an end to the suffering'. This statement may have derived from the doctor's definition of 
physical harm (i.e. that by treating an older frail person one continues her or his suffering, and thereby causes physical harm). The husband had a different view, and in the interview argued that 'it is the duty of every doctor to save lives'. By saying this, he used a 'sub-warrant' to ground his claim. As with the story about the in-growing toenail, the man justified his claim about mistreatment partly by reference to a successful resolution: the life of his wife was saved, and the doctor was reported and given an official reprimand.

\section{Warrants about psychological harm}

\section{It is mistreatment to inflict psychological harm and/or display bad manners}

Claims grounded in warrants about psychological harm were primarily of two kinds. The first were descriptions of situations where staff displayed inappropriate manners in contact with the older care recipient. The second were occasions when complaints from the family members resulted in retaliation by staff members, including situations where fear of such reactions prevented care recipients or family members from complaining. Additionally, it was not uncommon for family members to include in their descriptions of mistreatment situations in which they themselves had been offended by the staff. Although such actions are not mistreatment of care recipients, it is important to note that some family members refer to them when providing data about claimed mistreatment. Claims grounded in the warrant about psychological harm were commonly associated with warrants about physical harm. As a female interviewee recollected:

It was not long ago that he had been sick, and it was all dried in his bed. And dad told us, he thought it was disgusting and it made him feel uncomfortable but nobody came to help him, even though he tried to get some help. ... Dad is a bit dizzy, but still he says that: 'I don't want to say anything because if I do they are not nice to me. I can't. It is better [that] I pretend to be happy and sing a little'.

The interviewee began the account by expressing moral indignation, because her father had been left in his bed for several hours in his vomit. As her story continued, however, more claims were made as she described her fear of the staff. This is an example where warrants about physical and psychological harms overlapped; the bad care was described as a result of fear of the staff not being 'nice' to the care recipient if the recipient or the recipient's family complained. The fear of or experience of retaliation were frequently described in the interviewees' stories of mistreatment, and there were several reports that the staff had stopped talking to a care recipient as a reprisal for being criticised about some aspect of care. This construction of an argument is particularly interesting when investigating 
a family member's perspective on mistreatment in the context of the guardianship role of family members. Psychological mistreatment is, from the relatives' perspective, a risk associated with fulfilling the role as a guardian of identity. Many of the interviewees' stories of their struggles to assure decent care for their loved ones included strategies to avoid the staff's retaliation.

\section{Warrants about social-care deficiencies}

\section{It is mistreatment to fail to meet the social needs of care recipients}

Some family members claimed that staff turnover and a lack of continuity among care workers decreased the quality of life of their loved ones and amounted to cases of mistreatment. They invoked warrants about socialcare deficiencies linked to a lack of privacy, continuity and predictability, and also stated that there were too few activities for their relatives. These claims were presented in part as general reflections about the state of a facility, but there were also claims of harm, as when a resident had complained about being bored or isolated, and with complaints that the rules and routines of formal care were incompatible with the needs of the care recipients. For instance, some interviewees were worried that the television set was turned on to serve 'as a baby-sitter', with the result that the residents were passive and the ambience noisy and confusing. A typical way of framing claims about social-care deficiencies was to explain that although the residents were kept clean and healthy, there was insufficient time or ambition to attend to the psycho-social aspects of care.

Institutional routines mentioned as problematic included bedtimes, the arrangements for meals, and the staff's attitudes about family members' visits at certain times of the day. Similar to the cases discussed previously, claims about mistreatment that related to warrants about social-care deficiencies included descriptions about actions taken by the family member. For instance, one woman complained that when the nursing-home staff perceived her husband to be tired, he was left in bed all day long, which deprived him of social stimuli. She said, 'I think it is so very unfortunate. I mean, even if he is tired he could always sit up during the time when he is eating to see some other people, rather than just lying alone in his room, staring at the ceiling'. She had also developed a strategy to communicate her wishes without offending the staff: 'Well I wanted to be on good terms with them so I thought all the time that praise is better perhaps than complaint. So if he was sitting up among the others, I gave them credit: "How lovely that Karl is sitting up today", I would say when I went in'. 


\section{Warrants about identity subversion}

It is mistreatment to subvert the identity of a care recipient through a lack of respect for their personality and habits

Our analysis revealed that several claims about mistreatment were grounded in the implicit or explicit opinion that the older person's identity and habits should be maintained while he or she is in formal care. When describing mistreatment, some family members compared perceived deficiencies to how things 'used to be', and referred to what they perceived as subversions of the relative's identity. The interviewees recounted attempts to inform care providers about the personality, history, habits and preferences of a care recipient to facilitate good care and care with dignity. In many cases, these descriptions were used to explain why things worked well or had improved; in other cases, descriptions of futile attempts were used to back their claims about mistreatment. A distinctive characteristic of claims grounded in warrants about identity-subversion is the problem of official legitimatisation. Claims grounded in warrants regarding physical or psychological harm can be legitimised by reference to mainstream definitions, legislation and policies about the minimum standards of old-age care. Habits and identity are more individual: what is important to one person might be irrelevant to another. Furthermore, individual identity and habits may be subject to change, based on time passed as well as personal decisions on how to adapt to a special situation (e.g. holidays, formal occasions and institutionalisation).

In contrast to claims grounded on warrants about physical or physiological harm, many grounded in identity maintenance warrants were characterised by descriptions of how things used to be, for example, 'my husband always used to ...', 'I know that mother never liked to ...' and 'it has always been important for my wife to ...' They also invoked statements about ideal care of frail older people, very often with reference to ways of maintaining the older person's individuality. Claims were built upon comparisons: between 'here and there' ('at home he used to get up at $7 \mathrm{am}$, but in the nursing home he has to stay in bed until ro o'clock'), between 'now and then' ('before, he always used to go for a morning walk and now he only gets out once a week'), and between 'me and them' ('I know from experience that there is no point putting my husband on a diet, but the staff think he has to lose weight'). These comparisons between inside and outside the home echoed Goffman's analysis of how the selves of residents are structured by total institutions (Goffman I99I). The institutional moulding of a family member was perceived as undesirable by several interviewees, and as something that could constitute 
mistreatment. Further analysis of the data identified three categories of identity maintenance that the interviewees invoked when describing mistreatment: maintenance of appearance, maintenance of daily routines, and maintenance of preferred activities.

\section{Maintaining a person's appearance}

Some family members expressed dissatisfaction with the change in the appearance of the care recipient in the formal care setting. These claims were grounded in the importance of maintaining the way a particular person used to take care of his or her personal appearance or home. The interviewees did not argue that all people should be cared for in a certain way, but rather that they, as family members, had particular knowledge about the appearance of the person who received care and that this appearance should be maintained. Some claims in this category were in conflict with other warrants, as for the previously mentioned interviewee who talked about the clothes that the staff made her father wear:

He has never worn a T-shirt ... they dress him in a T-shirt and a pair of tracksuit pants and he has never worn those. A T-shirt is almost like a pair of underclothes and not something you walk around in ... and then they dressed him in tracksuit pants and a T-shirt all day long. So eventually we took these clothes away. He can't sit there in tracksuit pants, just because they are easy to put on, it's ridiculous!

The interviewee stated that her father 'never' used to wear T-shirts and tracksuit pants, and this constituted the justification for the warrant about identity subversion - he was simply not a person that would wear such clothes. Implied here is that the staff violated his personality for reasons of convenience, but the staff might regard a request to dress the care recipient in a shirt and tie as mistreatment, and refer to a warrant about avoiding physical harm. A shirt and tie may be uncomfortable for a frail older resident, while a $\mathrm{T}$-shirt and tracksuit pants might reduce the risk of pressure sores. Although this particular story did not recognise the incompatibility of the warrants, it is possible to argue from a family member's perspective for the right of a care recipient to dress in a way that is uncomfortable, because he or she has chosen to dress in this way during their lifetime. The situation described above also illustrates how conflicts between staff and family members arise. Numerous studies have described how the interaction between staff and family produces tensions and even conflicts (Bowen I978; Duncan and Morgan I994; Gladstone and Wexler 2002; Gubrium 1975; Savishinsky 199I; Utley-Smith et al. 2009), but few have related these conflicts to normative grounds or the supporting 
warrants. The staff may believe that the daughter exaggerated the importance of her father's clothing, but from the daughter's point of view, her concern may not have been at root a matter of clothing but rather a matter of identity subversion.

Another interviewee described her experience of witnessing mistreatment by explaining the importance of maintaining her husband's shaving routine. Her husband used to shave with a safety razor, not an electric razor, and he had always shaved twice a week. After describing how the staff violated these habits, she concluded 'sometimes they don't ask him and just use an electric razor.... I think that is a bit of an insult'. Without the personal information, few people would argue that there is anything wrong with using an electric razor unless the resident protests, but by stating how things 'used to be', the interviewee supported her claim that insult had occurred. The claim also deployed the 'me and them' device in claims-making. The interviewee said that she had told the staff about her husband's shaving preferences and by using the phrase, 'I know', she claimed exclusive knowledge of the resident's preferences and that this disqualified the staff's attempts to justify their decisions on the basis of the care recipient's responses. The assertion of her husband's preferences may also be seen as a way of maintaining her identity as a wife and their shared identity as a couple. By visiting the nursing home and giving information about her husband's preferences, she reaffirmed their continuing spousal relationship (compare with Whitaker 2009).

Warrants about the maintenance of appearance were also used in complaints about the state of the residents' rooms and the communal areas. One interviewee backed her claim that the less than thorough cleaning amounted to mistreatment by stating that her mother 'always used to have such a tidy home. ... They never cleaned the toilet. That was something I always had to do when I visited mum. Mum was really sad since she always used to have such a tidy home'. As with many allegations of mistreatment, it was not any home, any food or any habits that had been violated, but rather it was implied that mistreatment had occurred or was particularly abhorrent because it violated the individual's persona. The dirty toilet made the mother sad since she always had such a tidy home. Personal history was used as a standard in making this claim. Note also that the quotation represents the interviewee as a 'victim' of the alleged mistreatment. Although the daughter described how the dirty toilet made her mother upset, she also pointed out that it affected her, because she had to do the cleaning. The daughter's attempts to make the staff clean the toilet produced conflict; the daughter was labelled a trouble maker and the mother was told that she was ungrateful. 


\section{Maintaining a person's daily routines}

Moving into an institution or receiving assistance or formal care at home inevitably brings changes in a person's daily routines, for instance with sleeping or eating times. Some such changes that violated the previous daily routines of the person receiving care were seen as mistreatment. In one case, an interviewee stated that her father was being mistreated because he did not get out of the nursing home as much as he liked, and could no longer take his daily walk. This break in routine constituted the grounds for her claim about mistreatment. The daughter strengthened her claim by detailing her father's former daily routines:

And to think that when dad lived at home, until he had his stroke he went for a half-hour walk every morning and every afternoon. He has always enjoyed spending time outdoors, and now all the time, he tells us, 'I feel like a prisoner here. I don't go anywhere, I don't see anything, [and] I can't do anything'.

By stating that her father 'always enjoyed spending time outdoors', the daughter created a rhetorical context for her claim and used a warrant of maintaining identity and daily habits. Nowhere in the claim was it argued that older people in general should be given the opportunity to spend time outdoors; rather, it was argued that the particular person needs to be outdoors to maintain his daily routines. When the interviewees argued that the staff did not maintain an older person's daily routines, their backing arguments were carefully selected. Many included statements about how many years the interviewee had known the care recipient, and that the staff lacked or ignored this personal knowledge.

As in several other of the interviewees' stories, the daughter's claim about her father's 'imprisonment' was justified using what Pomerantz (I986) termed 'extreme case formulations', expressions that use hyperbolic terms such as all, none, everything, nothing, never and always, particularly when a conclusion was challenged. Extreme case formulations invoke a maximum or minimum of attributes of a person or event, and are therefore powerful devices for orally attributing blame, as when the daughter asserted that 'he has always enjoyed spending time outdoors, and now all the time, he tells us, 'I feel like a prisoner here. I don't go anywhere, I don't see anything, [and] I can't do anything'. Changes in the care recipients' daily routines were usually described as undesirable, but there were exceptions. For instance, one interviewee commented that her husband 'used to smoke when he moved in, but they made him quit, which I think was good'. This quote relates to the warrant about physical harm, for smoking is generally regarded as a health hazard. From the position of maintaining habits and identity, however, it is also possible to argue that forcing the resident to quit smoking constituted mistreatment. 


\section{Maintaining a person's preferred activities}

A third aspect emphasised by the interviewees was to maintain the older person's 'leisure' activities. Although the talk of daily routines and 'leisure' activities overlapped, the categories have distinctive dimensions. Some interviewees reinforced their claims about social-care deficiencies by referring to a lack of social activities and to a warrant about the importance of maintaining the preferred activities of the individual, which included complaints about a person being exposed to activities in which he or she would not normally engage. One woman claimed that activities other than bingo must be arranged in a residential home. She described her husband as an intellectual, and because he had never played bingo before, the wife could see no reason why he should start playing the game:

He used to study Russian in his spare time. When he retired he started to study at the university, so you can imagine his energy. I can understand that it can be difficult to (keep him occupied). He does not like to play bingo, which they think is the only thing older people do. I mean, there have to be other things to do [than] play bingo. I mean, he would never play bingo ... it can be difficult for a person like him.

As in the previous extracts, the story's phrasing includes extreme case formulations: 'bingo is the only thing they think old people do', and 'he would never play bingo'. These have a legitimating function, and the claim would have been weaker without the phrases. In her claim, the woman argued that alternative activities should be provided, but should the listener disagree with the identity maintenance warrant that grounded her claim, the conclusion would be unpersuasive and the claim might be dismissed as a petty complaint.

A similar argument was made about the use of the television in care facilities. Adding to the general criticism of using the television set as a 'babysitter', i.e. to substitute for adult contact, some interviewees criticised the choice of programmes, saying variously that they were too violent, or that some channels were selected to meet the staff's preferences. In the next quotation, the interviewee acted as a guardian of her husband's identity by adding her personal knowledge. To turn on the MTV channel without considering what kind of programme her husband used to watch was a source of tension between the wife and the staff:

On one occasion when I visited, there was a young girl feeding him and she had turned the television to MTV. I can never believe that he would have chosen that programme, but of course it was fun for her. And maybe my husband didn't care, but I found it a bit disturbing.

It is interesting that the interviewee doubted whether the programme disturbed her husband, who suffered from dementia. It could be argued 
that this reflection displays the interviewee's suspicion that she was projecting her own dislike on to her husband. Another interpretation would be to regard her reservation as proof that she is struggling with her 'guardianship role' and her mission to keep her husband's identity as intact as possible by protesting against non-preferred activities.

\section{Warrants that conflict}

As shown in the example regarding proper clothes, identity maintenance warrants were used to overrule warrants about physical care. One implication is that some interviewees may not have mentioned possible examples of mistreatment (that others would identify) because they judged that an action or condition did not insult their relative's persona or identity. Claims that the staff's actions were not mistreatment were made when they were deemed acceptable to the resident. For instance, when trying to define psychological mistreatment, one interviewee stated that behaviour that would normally count as 'abusive' had a different meaning for his father-in-law:

Psychological abuse to me is when people don't see you as you are - that nobody is listening, that nobody has the time. That is psychological abuse to me. That is much worse than saying, 'Sit down, old buffer!' That is not abusive to my father-in-law. [He and I] speak that way [with] each other. $\mathrm{He}$ thinks it is really funny if the staff say, 'old man Svensson, stay where you are!' He likes that and gets back at you. So it is blurred, this thing of psychological abuse.

This reasoning confounds the use of objective criteria to identify psychological mistreatment. Similarly, some family members backed claims about social mistreatment with reference to specific knowledge about a care recipient's personal characteristics. Arguing against the idea among staff that the wishes of the individual should be respected and that persistent or tough persuasion could constitute psychological mistreatment, some family members stated that they knew what the care recipient actually wanted, or that persuasion had always been the normal and accepted way of ensuring his or her compliance.

The examples point to some problematic aspects in family members' involvement in care. The transferability of a person's preferences from being at home and to living in an institution cannot be taken for granted. Is the fact that someone always had to be coerced to do a certain thing when living at home proof that he or she 'wants' to be pushed and persuaded when living in a nursing home? Claims that the nature of an older 
person justifies ignoring their opinions could in some cases constitute 'techniques of neutralisation' (Tomita I990), as have been identified in justifications of bullying in dysfunctional families. In one of the discussed examples, the old man had been a resident at the nursing home for more than a decade and the daughter's claim that the staff did not respect his personality could well be seen as denial of his change. Many long-term recipients lose cognitive and physical abilities, and it is important to understand that 'identity preservation' may be driven by fear, grief and desperation among family members, regardless of how care is arranged.

\section{Conclusions}

To end the paper, we comment on the contribution of our study to research on mistreatment, and discuss some challenges related to the role and perspective of family members in relation to formal elder care. In a recent study of elder mistreatment in the United Kingdom, Penhale (2008) argued that the meanings ascribed to situations by individuals are crucial components in the understanding of elder mistreatment. According to Penhale, a striking difference between elder abuse and spouse abuse is that non-professionals have played a key role in defining spouse abuse. We suggest that research on elder mistreatment from the perspectives of family members valuably complements current understanding that is largely based on the perspectives of professionals.

This study has identified several warrants that are used by family members to justify their claims of mistreatment, and found that they raise considerable difficulties for the use of objective criteria to identify and measure elder mistreatment. Mainstream definitions of the problem run the risk of being one-dimensional and of being biased by professionals' views. Using a rhetorical analysis originally developed by Toulmin (2003), this study has shown that family members to some extent use specific normative grounds when they construct the problem of elder mistreatment. Even if some had accepted that by consenting to their relative's admission to residential care they had 'given away' their relative, most nonetheless argued that the person's identity should be maintained. In their claims, they described their private knowledge about the older person, which they argued formal care providers needed to respect. By reference to 'identity maintenance' warrants, some family members tried to protect what they perceived as a 'sacred core' of the care recipient's self - which recalls Goffman's (I959) 'sacred self' and how this self is threatened in residential institutions. In their role as guardians of dignity, 
family members used their personal knowledge not only to maintain the older person's identity, but also as a foundation in their argumentation about mistreatment. Uncovering normative grounds in claims-making might provide a point of departure for future discussion regarding what aspects family members, and other actors, perceive as most important for good quality care.

Having emphasised the role of family members in formal care, a word of caution is needed. People change, and family members may for different reasons be reluctant to accept these changes. Identity, as Wellin and Jaffe (2004) noted, can be regarded both as an object and as a process. Formal carers, and in particular those working in institutions, may overemphasise identity as a process and mistake institutional moulding for 'natural' change among residents. Family members, on the other hand, may over-emphasise the transferability of a relative's past preferences into the institutional setting. When aiming to provide person-centred care for people who have little ability to express their opinions, it may be tempting to regard family members as a substitute voice (or those who reveal) the care recipient's true identity. Our study shows that, although the unique knowledge of family members provides valuable information that can improve care arrangements, the function is accompanied by practical and ethical problems.

Professionals in care work sometimes regard family members as too interventionist, and argue that they make egoistic, unrealistic and trivial claims with respect to care arrangements (Hammarström 2006; Whitaker 2004). The interaction between staff and family can produce tensions and conflicts (Duncan and Morgan 1994; Gladstone and Wexler 2002; UtleySmith et al. 2009). From our analysis, it is clear that some complaints that staff may label 'annoying' or 'petty' could be reframed and treated as part of the greater project of guarding and preserving the identity of care recipients. From the professional care-giver's perspective, the challenge is to understand the intention of requests and complaints among family members, and to respect the intention to preserve the sacred self even where it is inconvenient or generates more work. By acknowledging the project of preserving identity as an important phenomenon that affects relations in old-age care, some conflicts between family members and care workers may be understood and avoided.

\section{Acknowledgements}

The study was sponsored by the Swedish Council for Working Life and Social Research. 


\section{NOTES}

I Five interviews exceeded 70 minutes and six were shorter than $5^{\circ}$ minutes. Couples (husband and wife) were co-interviewed in two cases. Some interviewees spoke about more than one family member care recipient. The two authors contributed equally in the analysis and in writing this paper.

2 The study was approved by the Linköping Research Ethics Vetting Board (2006-0228, Dnr 19/o6). Participants were informed about the aim of the study and their ability to end participation at any time without stating a reason. Locations for interviews were chosen by participants; ig interviews took place in the home of the interviewee, one took place at an interviewee's workplace, and one took place on the premises of a voluntary organisation. Interviews were transcribed verbatim. Transcribed interviews were sent out to enable comments and clarifications from interviewees. Three participants made such clarifications.

3 Our translations and paraphrasing of the interviewees' statements.

\section{References}

Adams, T. 2005. From person-centred to relationship-centred care. Generations Review, I5, I, 4-7.

Åkerström, M. I996. Triader och typifieringar-Anhöriga som sociala verktyg, kunskapskällor, medbehandlare och 'extra-patienter' i ett vårdkontext [Triads and characterisations: family members as social tools, sources of knowledge, co-therapists, and 'extra patients' in a care context]. Socialvetenskaplig Tidskrift, 3, 4, 287-300.

Baker, M. and Heitkemper, M. 2005. The roles of nurses on interprofessional teams to combat elder mistreatment. Nursing Outlook, 53, 5, 253-9.

Best, J. 1990. Threatened Children: Rhetoric and Concern About Child-victims. University of Chicago Press, Chicago.

Boise, L. and White, D. 2004. The family's role in person-centered care: practice considerations. Fournal of Psychosocial Nursing and Mental Health Services, 42, 5, I2-20.

Bowen, M. 1978. Family Therapy and Clinical Practice. Jason Aronson, New York.

Bowers, B. I988. Family perceptions of care in a nursing home. The Gerontologist, 28, 3, $3^{6} \mathrm{I}-8$.

Brogden, M. and Nijhar, P. 200o. Crime, Abuse and the Elderly. Willan, Cullompton, UK.

Cooper, C., Selwood, A. and Livingston, G. 2008. The prevalence of elder abuse and neglect: a systematic review. Age and Ageing, 37, 2, I5 I-60.

Davies, S. and Nolan, M. 2003. 'Making the best of things': relatives' experiences of decisions about care-home entry. Ageing \& Society, 23, 4, 429-50.

Duncan, M. T. and Morgan, D. L. I994. Sharing the caring: family caregivers' views of their relationships with nursing home staff. The Gerontologist, 34, 2, 235-44.

Eliasson, R. 1995. Forskningsetik och perspektivval [Research Ethics and Choice of Perspective]. Studentlitteratur, Lund, Sweden.

Gearing, B. 1995. Elder Abuse in Perspective. Open University Press, Buckingham, UK.

Gladstone, J. and Wexler, E. 2002. Exploring the relationships between families and staff caring for residents in long-term care facilities: family members' perspectives. Canadian fournal on Aging, 2 I, I, 39-46.

Glendenning, F. I997. What is elder abuse and neglect? In Decalmer, P. and Glendenning, F. (eds), The Mistreatment of Elderly People. Sage, London, I3-4I.

Glendenning, F. 1999. Elder abuse and neglect in residential settings: the need for inclusiveness in elder abuse research. Fournal of Elder Abuse and Neglect, ro, I/2, I-I I. 
Goffman, E. 1959. The Presentation of Self in Everyday Life. Doubleday, New York.

Goffman, E. I991. Asylums: Essays on the Social Situation of Mental Patients and Other Inmates. Penguin, Harmondsworth, UK.

Gubrium, J. 1975. Living and Dying at Murray Manor. St. Martin’s Press, New York.

Gubrium, J. and Holstein, J. 1997. The New Language of Qualitative Methods. Oxford University Press, New York.

Hammarström, G. 2006. 'Det är ständiga bekymmer man har med anhöriga': Ambivalens gentemot äldres barn bland personal i kommunal äldreomsorg ['There are constant problems with the relatives': ambivalence towards older people's children among staff in old-age care]. Gerontologia, 20, 3, 130-7.

Harbison, J. and Morrow, M. 1998. Re-examining the social construction of 'elder abuse and neglect': a Canadian perspective. Ageing $\mathcal{E}^{2}$ Society, I8, 6, 69I-7I I.

Hertzberg, A. and Ekman, S.-L. 2000. 'We, not them and us?' Views on the relationships and interactions between staff and relatives of older people permanently living in nursing homes. Fournal of Advanced Nursing, 31, 3, 6I4-22.

High, D. M. and Rowles, G. D. 1995. Nursing home residents, families and decision making: toward an understanding of progressive surrogacy. Fournal of Aging Studies, 9, 2, IOI-I7.

Hudson, M. F. I991. Elder mistreatment: a taxonomy with definitions by Delphi. Fournal of Elder Abuse and Neglect, 3, 2, I-20.

Hugman, R. 1995. The implications of the term 'elder abuse' for problem definition and response in health and social welfare. Fournal of Social Policy, 24, 4, 493-507.

Hydle, I. and Johns, S. I993. Övergrepp mot äldre - Stängda dörrar och knutna nävar: Om misshandel $i$ hemmet [Elder Abuse. Closed Doors and Clenched Fists: Domestic Violence]. Studentlitteratur, Lund, Sweden.

Isola, A., Backman, K., Voutilainen, P. and Rautsiala, T. 2003. Family members' experiences of the quality of geriatric care. Scandinavian Fournal of Caring Sciences, 17, 4, 399-408.

Jönson, H. 2006. Vårdskandaler $i$ perspektiv: Debatter om vanvård, övergrepp och andra missförhållanden inom äldreomsorg [Nursing Home Scandals in Perspective: Debates About Abuse, Neglect and Other Bad Conditions in Formal Care]. Égalité, Malmö, Sweden.

Lachs, M. S. and Pillemer, K. 2004. Elder abuse. The Lancet, 364, 944I, I263-72.

McCormack, B. 2003. A conceptual framework for person-centred practice with older people. International Fournal of Nursing Practice, 9, 3, 202-9.

Nandlal, J. M. and Wood, L. A. I997. Older people's understandings of verbal abuse. Fournal of Elder Abuse and Neglect, 9, I, I7-3I.

National Care Homes Research and Development Forum 2007. My Home Life: Quality of Life in Care Homes. A Review of the Literature. Prepared for Help the Aged by The National Care Homes Research and Development Forum, London. Available online at http:// www.myhomelife.org.uk [Accessed io February 2009].

Penhale, B. 2008. Elder abuse in the United Kingdom. Fournal of Elder Abuse and Neglect, 2o, $2, \mathrm{I} 5 \mathrm{I}-68$.

Phillips, C. D., Kimbell, A.-M., Hawes, C., Wells, J., Badalamenti, J. and Koren, M. J. 2008. It's a family affair: consumer advocacy for nursing-home residents in the United States. Ageing E Society, 28, I, 67-84.

Pillemer, K. and Moore, D. W. I989. Abuse of patients in nursing homes: findings from a survey of staff. The Gerontologist, 29, 3, 3I4-20.

Plitnick, K. R. 2008. Elder abuse. AORN Journal, 87, 2, 422-7.

Pomerantz, A. I986. Extreme case formulations: a way of legitimizing claims. Human Studies, 9, 2-3, 219-29.

Robb, B. 1967. Sans Everything: A Case to Answer. Nelson, London.

Roe, B. 2002. Protecting older people from abuse. Nursing Older People, I4, 9, I4-18. 
Rolland, J. S. 1994. Families, Illness, and Disability: An Integrative Treatment Model. Basic, New York.

Saveman, B. I. 1994. Övergrepp mot äldre i hemmet ur distrikssköterskors perspektiv [Maltreatment of Home-dwelling Older People as Seen by Community Nurses]. AKA-Print, Arhus, Sweden.

Saveman, B. I., Åström, S., Bucht, G. and Norberg, A. I999. Elder abuse in residential settings in Sweden. Fournal of Elder Abuse and Neglect, r о, I, 43-60.

Savishinsky, J. S. I991. The Ends of Time: Life and Work in a Nursing Home. Bergin and Garvey, New York.

Sellers, C., Folts, E. and Logan, K. I992. Elder mistreatment: a multidimensional problem. Fournal of Elder Abuse and Neglect, 4, 4, 5-20.

Shore, P. and Santy, J. 2004. Orthopaedic nursing practice and elder abuse. Fournal of Orthopaedic Nursing, 8, 2, I03-8.

Teaster, P., Lawrence, S. and Cecil, K. 2007. Elder abuse and neglect. Aging Health, 3, I, II $5-28$.

Tomita, S. K. I990. The denial of elder mistreatment by victims and abusers: the application of neutralization theory. Violence and Victims, 5, 3, I7 $1-84$.

Toulmin, S. 2003. The Uses of Argument. Cambridge University Press, Cambridge.

Townsend, P. 1962. The Last Refuge. Routledge, London.

Utley-Smith, Q., Colón-Emeric, C. S., Lekan-Rutledge, D, Ammarell, N., Bailey, D., Corazzini, K., Piven, M. L. and Anderson, R. A. 2009. Staff perceptions of staff: family interactions in nursing homes. Fournal of Aging Studies, 23, 3, I68-77.

Wellin, C. and Jaffe, D. J. 2004. In search of 'personal care': challenges to identity support in residential care for elders with cognitive illness. Fournal of Aging Studies, r 8, 3 , 275-95.

Whitaker, A. 2004. Livets sista boning: Anhörigskap, åldrande och död på sjukhem [The Last Home: Family Ties, Ageing and Death in a Nursing Home]. Institutionen för socialt arbete, Stockholm.

Whitaker, A. 2009. Family involvement in the institutional eldercare context: towards a new understanding. Fournal of Aging Studies, 23, 3, I58-67.

Address for correspondence:

Accepted 24 August 2009

Tove Harnett, Institute of Gerontology,

School of Health Sciences, Jönköping University,

Box I026, S-55 I I , Jönköping, Sweden

E-mail: Tove.Persson@hhj.hj.se

\section{Editor's note:}

To reduce confusion for decades to come, when this paper was submitted the first author's family name was Persson, but before it was published she married and adopted the name Harnett. 